\title{
Análise do perfil de gestão em empresas de comércio e serviços da Microrregião do Vale do Itapocu
}

\author{
Einstein Randal Pereira Gomes' \\ Jonas de Medeiros ${ }^{2}$ \\ Jucelaini Pötter ${ }^{3}$ \\ Camila de Cássia Silva Cristiano ${ }^{4}$ \\ Jackyane Marquardt ${ }^{5}$ \\ José Renato do Amaral ${ }^{6}$ \\ Juliete Dolzan ${ }^{7}$
}

\section{RESUMO}

As empresas, de maneira geral, têm por motivação sobrevivência e competitividade em um mercado em constante metamorfose. 0 perfil das empresas e empresários tem se modificado constantemente, buscam-se novos desafios, novas metas e novos mercados. Os gestores da Faculdade de Tecnologia Senac Jaraguá do Sul, contextualizada ao norte de Santa Catarina, pretenderam focar seus esforços em identificar o perfil das empresas de comércio e serviço da microrregião do Vale do Itapocu, caracterizando-as. Desse modo, ao buscar identificar o perfil de gestão das empresas participantes do estudo, bem como os de seus principais gestores, a Faculdade buscou alinhar-se a tal perfil. Metodologicamente, a pesquisa se caracterizou por ser de natureza exploratória, tendo como algumas de suas hipóteses: (a) a maioria das empresas da microrregião segue modelos de gestão não formalizados, com respostas predominantemente tácitas ao mercado; (b) embora seja crescente a busca por conhecimento profissional, a prática ainda carece de bases teóricas. A análise dos dados demonstrou um grau superior de capacitação por parte de gestores e colaboradores das empresas, em vista daqueles que inicialmente se esperava encontrar, mostrando proatividade do setor de comércio e serviços microrregional, em termos da necessária evolução ao que o mercado de consumo vem demandando. Ainda, estratificados os dados apenas para os setores de comércio e serviços microrregionais, a amostra constituiu-se de empresas majoritariamente do comércio (66\%), com faixa de faturamento de até R \$ 244 mil/ano (50\%), com até nove funcionários (49\%) e há mais de dois anos de atividade (92\%).

Palavras-chave: Gestão Estratégica. Diagnóstico Empresarial. Comércio e Serviços.

\footnotetext{
1 Mestreem Administração-gomes.randal@uol.com.br

2Especialista em Comunicação Integrada de Marketing-jonasdemedeiros@gmail.com

3 Especialista em Administração de Negócios -jucelainipotter@hotmail.com

4 Graduanda em Gestão da Tecnologia da Informação-camila_cassia@hotmail.com

5 Graduanda em Tecnologia de Processos Gerenciais-jack_yane@hotmail.com

6 Graduando em Tecnologia de Processos Gerenciais - joserenatoamaral@hotmail.com

7 Graduanda em Tecnologia de Processos Gerenciais -julietedolzan@hotmail.com
} 


\section{INTRODUÇÃO}

0 mercado está em constante metamorfose, de forma que as empresas, que têm por motivação sobrevivência e competitividade, adequaram o seu próprio perfil, como o de seus gestores, de modo a atender esse mercado em constante evolução. Contextualizada ao norte de Santa Catarina, a Faculdade de Tecnologia Senac Jaraguá do Sul visou identificar o perfil de gestão e de gestores, em empresas de comércio e serviços na microrregião do Vale do Itapocu, caracterizando-os e, assim, trazendo à luz do conhecimento acadêmico a práxis atual do mercado.

Desse modo, ao buscar identificar o perfil de gestão das empresas participantes do estudo, bem como os de seus principais gestores, procurou-se alinhá-los à necessidade de perfis profissionais qualificados para o mercado. Mediante a pesquisa desenvolvida, visou-se entender como a microrregião pode absorver profissionais egressos dos cursos oferecidos pela Instituição. Por outro lado, à medida que novas demandas emergem, podem-se adaptar os egressos a essa nova realidade, pois em geral o mercado absorve mão de obra de forma desordenada, sem o devido reconhecimento das capacitações realizadas.

Surgiu disso a necessidade de se estabelecer um rol de demandas das empresas da microrregião, já que na área de comércio e de serviços é a instituição Senac que tem por missão formar profissionais necessários ao desenvolvimento desses setores. Munidos de dados pontuais, a Instituição, seus parceiros, empresas da microrregião, gestores e acadêmicos têm condições de se adequar às realidades emergentes na área de comércio e serviços.

No início do desenvolvimento da pesquisa, de caráter exploratório, foram antevistas algumas hipóteses tácitas, aplicáveis à amostra de empresas do universo microrregional de negócios: (a) a maioria das empresas segue modelos de gestão não formalizados, com respostas predominantemente tácitas às demandas de mercado; (b) embora seja crescente a busca por conhecimento profissional, a prática ainda carece de bases teóricas; (c) há uma relação diretamente proporcional entre o porte das empresas estudadas, o grau de profissionalização de sua estrutura de gestão, e entre este grau e sua faixa de faturamento por período.

\subsection{Metodologia}

De acordo com os princípios metodológicos da pesquisa, seguiram-se os passos operacionais de Marconi e Lakatos (2007), em que as descrições do objeto de estudo podem ser tanto qualitativas quanto quantitativas e, na coleta de dados, podem ser utilizadas observações participantes, entrevistas, assim como análises de conteúdo. Objetivou-se a um instrumento que fosse capaz de analisar o perfil de gestão e gestores de empresas de comércio e serviços.

A pesquisa previu etapas de fundamentação bibliográfica, bem como pesquisa de campo, sendo o instrumento de coleta de dados (ICD) com questões abertas, numa primeira fase qualitativa, e questões fechadas, na segunda fase, quantitativa. Sobre a natureza quali-quantitativa do estudo, Gomes e Araújo (2010, p.10) pontuam que

\footnotetext{
o que se vêm observando na prática é um crescimento, ainda que de forma tímida, da demanda pelas metodologias quanti-qualitativas, ou, quali-quantitativas. Os pesquisadores que antes se colocavam nos extremos do continuum - positivismo/interpretativismo - estão se posicionando mais ao centro. Os resultados alcançados com o emprego dessas metodologias alternativas apontam para uma maior fidedignidade e validação das pesquisas. Se é certo que a verdade absoluta nunca é alcançada, talvez a utilização de abordagens múltiplas possa, ao menos, aproximar os pesquisadores de uma verdade temporal.
} 
Figura 1 - Desenho esquemático do Projeto

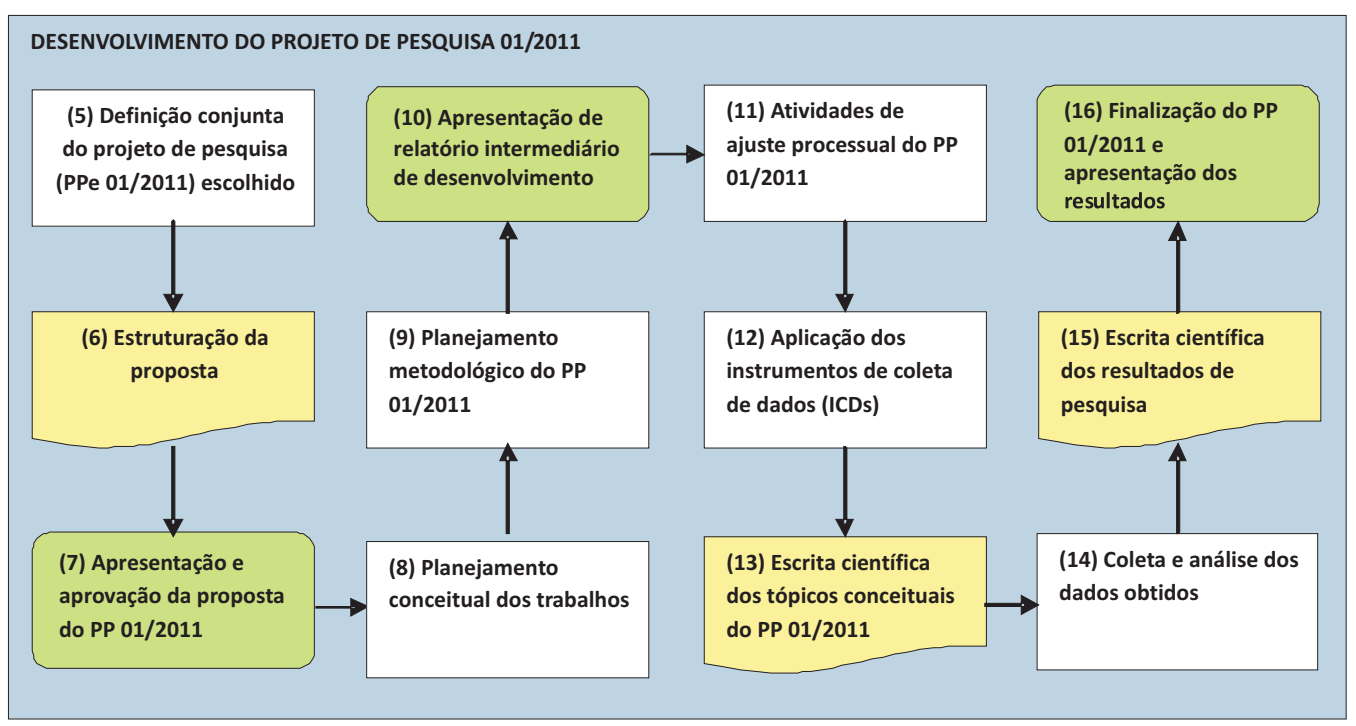

Fonte: Adaptado de Gomes, Krüger e Santos (2010)

Na pesquisa qualitativa, "a interpretação dos fenômenos e a atribuição dos significados são básicos [...]. 0 ambiente natural é a fonte direta para coleta de dados, e o pesquisador é o instrumento-chave. É descritiva" (DIEHL; TATIM apud GURGACZ; NASCIMENTO, 2007, p. 31). Na pesquisa de cunho descritivo, o pesquisador "terá que fazer um esforço de abstração, ultrapassando os dados, tentando possíveis explicações, configurações e fluxos de causa e efeito" (GIL, 2002, p. 134).

Metodologicamente, houve a capacitação dos acadêmicos participantes do Projeto de Iniciação Científica Senac (PIC Senac) em várias oportunidades durante o período, além das atividades de leitura e de entendimento do processo de pesquisa. Estabeleceu-se também que seriam coautores de todo o processo e igualmente da estruturação e aplicação das duas fases da pesquisa, abrangendo uma primeira etapa qualitativa (que foi ao encontro do que havia sido solicitado pelo Conselho Consultivo da Unidade) e uma segunda etapa quantitativa (que foi ao encontro do previsto quando do oferecimento do projeto ao Senac/DR).

Em agosto de 2011, foi realizado pré-teste do questionário quantitativo elaborado pela equipe de pesquisadores, no Curso de Pós-Graduação em Gestão de Projetos, que permitiu aos pesquisadores preencherem lacunas de entendimento existente, bem como simplificarem-no, para fácil compreensão dos respondentes. Após isso, foi feita a preparação da aplicação à amostra pesquisada (numeração/envelopagem), de forma a manter controle geral do processo de pesquisa em suas várias fases, assim como o estabelecimento de pontos de checagem e monitoramento.

Essa etapa visou também a capacitação dos acadêmicos do PIC Senac, como tutores da aplicação do ICD e interface junto aos facilitadores. Por fim, na etapa de tratamento dos dados, houve a tabulação e análise dos dados obtidos, que permitiram o aprofundamento no tema de pesquisa e o cruzamento de dados, tendo em vista a Análise de Resultados posteriormente descrita. Os dados foram pré-apresentados para os orientadores e os discentes da Faculdade, por ocasião da III Semana Acadêmica Senac, de 16 a 18 de novembro de 2011.

\subsubsection{Amostragem da pesquisa}

Quanto à amostragem, para que tivesse validade intrínseca, objetivou-se verificar que critérios eram determinantes do porte empresarial e da caracterização das empresas. Percebeu-se que há a utilização de conceitos heterogêneos, decorrentes do fato de que a finalidade e os objetivos das instituições que promovem o enquadramento empresarial são distintos (IBGE, 2001).

Assim, o grupo de pesquisadores seguiu a metodologia do Instituto Brasileiro de Geografia e Estatística (IBGE), que procura analisar o porte empresarial pelo número de funcionários. Outras entidades, tais como Sebrae e BNDES, focam questões outras, tais como regulamentação da atividade econômica, perfil para 
concessão de crédito, estudos, etc., que excedem a proposta aqui estabelecida. Desse modo, o Quadro 1 resume a caracterização do grupo de empresas.

Quadro 1 - Classificação comparativa para micro e pequenas empresas

\begin{tabular}{|c|c|c|}
\hline $\begin{array}{c}\text { CRITÉRIOS DE } \\
\text { ENQUADRAMENTO }\end{array}$ & VALOR DE RECEITA & $\begin{array}{c}\text { NÚMERO DE PESSOAS } \\
\text { OCUPADAS }\end{array}$ \\
\hline $\begin{array}{l}\text { Lei no } 9.841 \text { de 05/10/1999 } \\
\text { - Microempresas } \\
\text { - Empresas de pequeno porte } \\
\end{array}$ & $\begin{array}{l}\text { - Até } 244 \text { mil reais } \\
\text { - De } 244 \text { mil reais a } 1.2 \text { milhões de reais }\end{array}$ & \\
\hline $\begin{array}{l}\text { SEBRAE } \\
\text { - Microempresas } \\
\text { - Empresas de pequeno porte }\end{array}$ & & $\begin{array}{l}\text { - Até } 9 \\
\text { - De } 10 \text { a } 49\end{array}$ \\
\hline $\begin{array}{l}\text { BNDES (critério dos países do Mercosul } \\
\text { para fins creditícios) } \\
\text { - Microempresas } \\
\text { - Empresas de pequeno porte }\end{array}$ & $\begin{array}{l}\text { - Até } 400 \text { mil dólares (cerca de } 940 \text { mil reais) } \\
\text { - De } 400 \text { mil dólares a } 3.5 \text { milhões de } \\
\text { dólares (cerca de } 8.2 \text { milhões de reais) }\end{array}$ & \\
\hline
\end{tabular}

Fonte: IBGE (2001)

Quanto aos questionários, foram inicialmente impressas novecentas unidades. Destes: (a) retorno esperado: duzentas unidades; (b) retorno alcançado: 263 unidades. Foram considerados válidos para a amostra, 192 unidades, pois na estratificação prevista, referiam-se a empresas da área de comércio e/ou serviços, foco do estudo.

\section{ESTRUTURAÇÃOESTRATÉGICADA GESTÃO}

A gestão empresarial é a estrutura-chave em torno da qual se mantêm os processos administrativos, responsáveis pelo fluxo de informações, dados e serviços que, em última análise, determinam o desempenho estratégico da organização. Assim, nesta seção, os autores buscaram evidenciar os principais conceitos que orientaram teoricamente a pesquisa.

\subsection{A estruturação empresarial e seu modelo de gestão}

De acordo com Oliveira (2009), os modernos modelos exigem, em elevada intensidade, o delineamento e operacionalização de estratégias que consolidem vantagens competitivas reais, sustentadas e duradouras para as empresas. A estratégia, por sua vez, é um plano para otimizar as ações de maneira a atingir um objetivo determinado. Segundo Glueck (1980), citado por Mintzberg et al. (2006), a estratégia é um plano unificado, amplo e integrado, criado para assegurar que os objetivos da empresa sejam atingidos.

Com base nessa definição, o autor concebe ainda que a estratégia empresarial é um processo inseparável da estrutura, do comportamento e da cultura da companhia na qual é realizada. Não obstante, podemos extrair desse processo dois aspectos importantes, interrelacionados na vida real, mas separáveis para efeito de análise: a de que os processos de planejamento empresarial são bastante diversos daqueles ligados à sua execução. 0 primeiro poderá ser chamado de formulação e o segundo, de implementação. Ainda, Andrews (2001, p. 58) define estratégia empresarial como

o padrão de decisões em uma empresa que determina e revela seus objetivos, propósitos ou metas, produz as principais políticas e planos para a obtenção dessa metas e define a escala de negócios em que a empresa deve se envolver, o tipo de organização econômica e humana que pretende ser e a natureza da contribuição econômica e não-econômica que pretende proporcionar a seus acionistas, funcionários e comunidades.

Sendo assim, as principais subatividades da formulação de estratégia como atividade lógica incluem a identificação das oportunidades e ameaças no ambiente da empresa, adicionando-se alguma estimativa ou risco às alternativas discerníveis. Conforme o autor, entretanto, a implementação da estratégia é composta de 
uma série de subatividades basicamente administrativas. Oliveira (2009), ao tratar a respeito da formulação de estratégias por parte das empresas, usa a metáfora da direção de um carro, no qual, com um para-brisas grande e um retrovisor pequeno, o passado é apenas uma referência, mas não uma direção.

A definição de uma estratégia empresarial é trabalhar de maneira a contemplar os objetivos definidos. Esse é um fator preponderante para o sucesso e crescimento organizacional nesse ambiente de competição acirrada em que as empresas estão inseridas atualmente. Assim, entende-se que as empresas que lideram em seus mercados de atuação são aquelas que trabalham de maneira diferenciada e oferecem algo inovador aos seus clientes.

\title{
2.2 A Gestão de pessoas e de processos na administração
}

A administração está em processo de mudança constante. Segundo Gil (2010, p. 31), “a ciência da Administração vem sendo cada vez mais desafiada a superar um número cada vez maior de problemas decorrentes da transição pela qual passa o mundo contemporâneo". Assim, a mudança no processo de administração, traz também a mudança na gestão de pessoas. 0 processo de inserção das pessoas na organização como parte do processo é demonstrado na simples mudança de nomenclatura. Conforme Chiavenato (2005, p.316),

\begin{abstract}
as pessoas estão ganhando uma variedade de denominação nas organizações. Em algumas poucas, elas são ainda chamadas de mão-de-obra para refletir o caráter mecânico, braçal e muscular. Outros ainda as denominam de funcionários - ocupantes de funções ou de cargos. Essas denominações estão parecendo hoje coisas do passado. Outras organizações preferem chamá-las de colaboradores, sócios ou parceiros para significar seu papel. Indo mais além, outras utilizam a denominação de talentos, competências, capital humano ou ainda capital intelectual. Na verdade, por trás da denominação está a maneira pela qual a organização visualiza e valoriza o papel das pessoas em suas atividades.
\end{abstract}

Mais do que nunca, a gestão de pessoas torna-se fundamental para as organizações, uma vez que veem o funcionário não somente como mão de obra, mas como participante da organização. Apresenta-se, dessa forma, uma mudança na cultura organizacional. De forma geral, esta é concebida como um conjunto de valores, normas, pressupostos e conhecimentos compartilhados, que constrói a identidade da organização (FLEURY, 1996).

Por outro lado, a capacitação profissional visa preparar mão de obra qualificada para o mercado, desenvolvendo assim o capital humano necessário à continuidade dos processos empresariais. Segundo Becker e Blaug, citados por Martins e Monte (2009), deve-se entender primeiro que o termo capital humano refere-se ao conjunto de capacidades produtivas dos seres humanos, formadas por seus conhecimentos, atitudes e habilidades que geram resultados em uma economia. Em sua essência, a Teoria do Capital Humano fundamenta-se no conceito de que a aquisição de mais conhecimentos e habilidades melhora o valor do capital humano das pessoas, aumentando sua empregabilidade, produtividade e rendimento potencial.

Da mesma forma Lima (2006), citado por Martins e Monte (2009), observa que a lógica da Teoria do Capital Humano é de forma sequencial: as pessoas se educam; suas "habilidades" e conhecimentos mudam, como efeito principal dessa educação. Quanto mais uma pessoa estuda, maiores são suas habilidades cognitivas e sua produtividade; e, essa maior produtividade lhes permite maiores rendas. Para que ocorra a transferência do conhecimento dos indivíduos, para a empresa por meio de socialização e codificação, alguns processos devem ocorrer. A empresa deve oferecer as condições capacitadoras necessárias, e a rede de relacionamento inicial que alavancou o negócio costuma estar associada a redes de conhecimento relacionadas ao campo do saber.

Lemos e Jóia (2009) afirmam que, para se entender a aplicação desse conceito perante a era do conhecimento, deve-se primeiramente entender de que forma o conhecimento é tratado, se apenas de modo teórico ou com efeitos práticos sobre a realidade analisada. Isso porque o conhecimento deriva da informação, da mesma forma que a informação deriva dos dados. Entretanto, é essencial a participação do ser humano na transformação de informação em conhecimento, o que envolve um nível de entendimento obtido por meio de experiência, familiaridade e aprendizado pessoais.

Dessa maneira, além de influenciado pelos indivíduos, o conhecimento é dependente do contexto social em que está inserido ou de uma situação específica. É, portanto, difícil de ser gerenciado, pois se origina e é aplicado nas mentes dos seres humanos. Entendendo isso, o conceito de era do conhecimento é ampliado e modificado pelas necessidades presentes tanto no mercado como na livre sociedade, impactando diretamente 
nos rumos da capacitação empresarial e no preparo de novos potenciais "capitais humanos".

\subsection{Empresas de comércio e serviços no Brasil}

Segundo SEBRAE/SC (2010), o setor terciário é o setor que mais cresce no mundo e também no Brasil; em 2006, respondia por 65,8\% do Produto Interno Bruto (PIB) do país. Fazem parte desse setor o ramo do comércio (varejo e atacado) e o de prestação de serviços, que integra setores como o turismo, os serviços financeiros, jurídicos, de informática, comunicação, arquitetura, engenharia, auditoria, consultoria, publicidade e propaganda, seguro, corretagem, transporte e armazenagem, além das atividades públicas e privadas de defesa, segurança, saúde e educação, entre outros.

Segundo dados do Ministério do Trabalho e Emprego relativos a 2008, o setor de comércio e serviços brasileiro totalizava 28.477.715 empregos, o equivalente a 72,2\% dos empregos formais do país. Nesse ano, as atividades de administração pública, defesa e seguridade social responderam por 29,3\% dos empregos do setor terciário (SEBRAE/SC, 2010).

Em Santa Catarina, tomando-se por referência dezembro de 2008, o comércio e a prestação de serviços (excluídas as atividades da administração pública, defesa e seguridade social e as de organismos internacionais e outras instituições extraterritoriais) eram responsáveis por 80,2\% das empresas do estado. Esses dois setores respondiam por $47 \%$ dos postos formais de trabalho de Santa Catarina.

No estado, os micro e pequenos empreendimentos do setor somam 99,4\% dos estabelecimentos. Por sua vez, as empresas desse porte são responsáveis por $64 \%$ dos empregos do setor. A Coordenadoria do SEBRAE Regional Norte abriga a maior parcela dos estabelecimentos ligados ao setor terciário catarinense, aproximadamente, $18 \%$. Por outro lado, o maior volume dos empregos gerados pelo setor (25\%) está na Grande Florianópolis.

\section{ANÁLISEDERESULTADOS}

Foram recebidos 263 questionários, dos quais 192 foram considerados válidos para efeito de estratificação da pesquisa; isso equivaleu a que as respostas indicavam área de atuação principal como Indústria e/ou Comércio. Assim, 58\% dos respondentes são do sexo masculino e $42 \%$ do sexo feminino e quanto à faixa etária $70 \%$ dos respondentes estão entre 25 e 44 anos de idade, subdivididos ainda conforme as faixas etárias identificadas na pesquisa.

Figura 2 - Perfil de escolaridade dos gestores e dos colaboradores

\section{PERFIL DE ESCOLARIDADE}

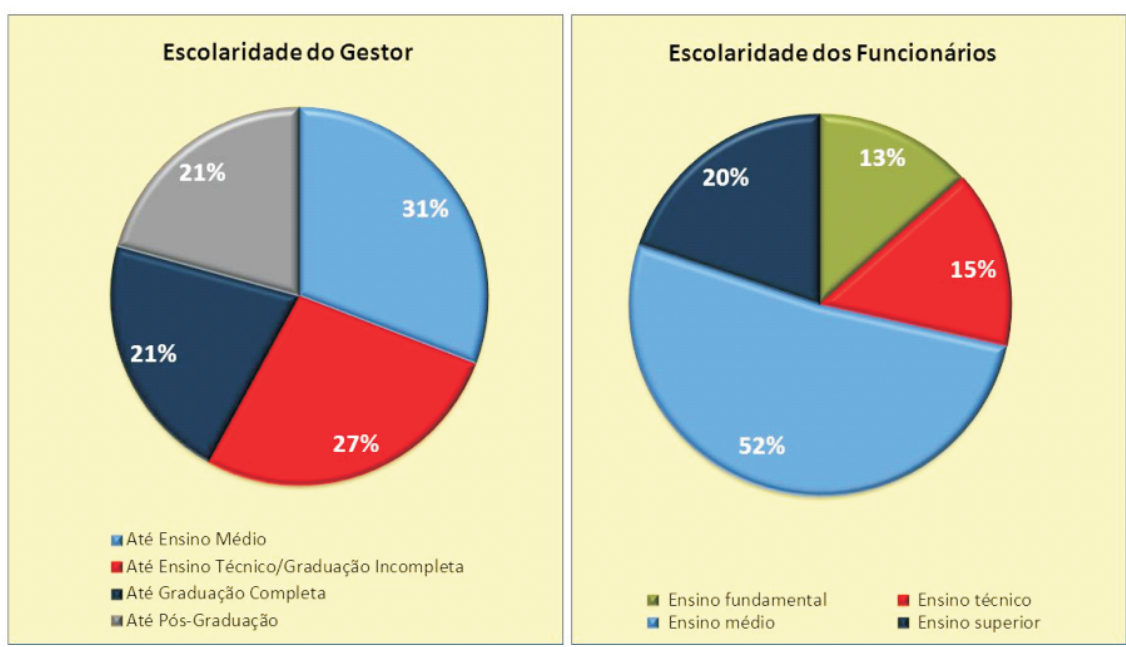

Fonte: Dados primários da pesquisa (2011) 
Quanto ao perfil de escolaridade, há uma divisão quase equalitária entre as diversas categorias, mas se pode perceber que há, para os gestores, uma ênfase no ensino técnico e superior (graduação e pós-graduação), de acordo com o demonstrado na Figura 2. Com isso, os pesquisadores puderam inferir que, além de faixa etária relativamente baixa, há capacitação profissional adequada por parte dos gestores pesquisados.

Isso se torna mais evidente, quando confrontados os dados de capacitação dos profissionais que trabalham nas empresas (Figura 2): 52\% deles têm o ensino médio completo, como grupo majoritário. Somando-se as diversas categorias, $87 \%$ têm escolaridade acima do nível fundamental, identificando um perfil de maior capacitação comparativa ao restante do Brasil (IBGE, 2001).

Em termos gerais, de acordo com os dados múltiplos indicados na Figura 3, pode-se perceber que os dados sumarizam empresas majoritariamente do comércio (66\%), com faixa de faturamento de até R\$244 mil/ano (50\%), com até nove funcionários (49\%) e há mais de dois anos de atividade (92\%). Especificamente quanto a este dado, é notável que mesmo havendo um conjunto de $25 \%$ de empresas em funcionamento de dois a cinco anos, $67 \%$ da amostra total indica um período superior de anos de atividade. Essa é considerada uma das descobertas da pesquisa, em que se pôde verificar a longevidade empresarial em termos dos setores estudados.

Figura 3 - Perfil das empresas da amostra

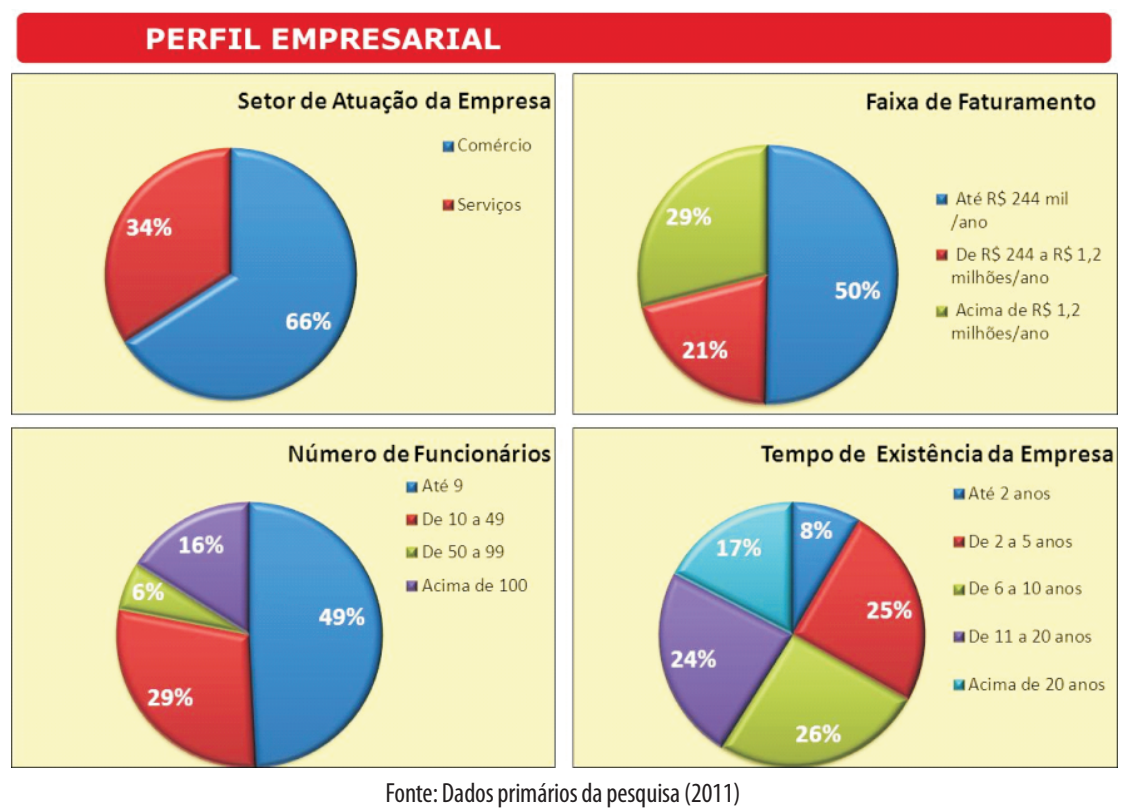

Quanto às ferramentas de Gestão, no grupo estudado pôde-se perceber que Metas e Resultados Financeiros, bem como Planejamento Estratégico são as duas mais utilizadas. Organograma Formalizado e Planejamento de Cargos e Salários estão presentes em parte da estrutura; porém, há uma tendência em não fazerem parte do cotidiano organizacional das empresas pesquisadas. 
Figura 4 - Importância das ferramentas de gestão

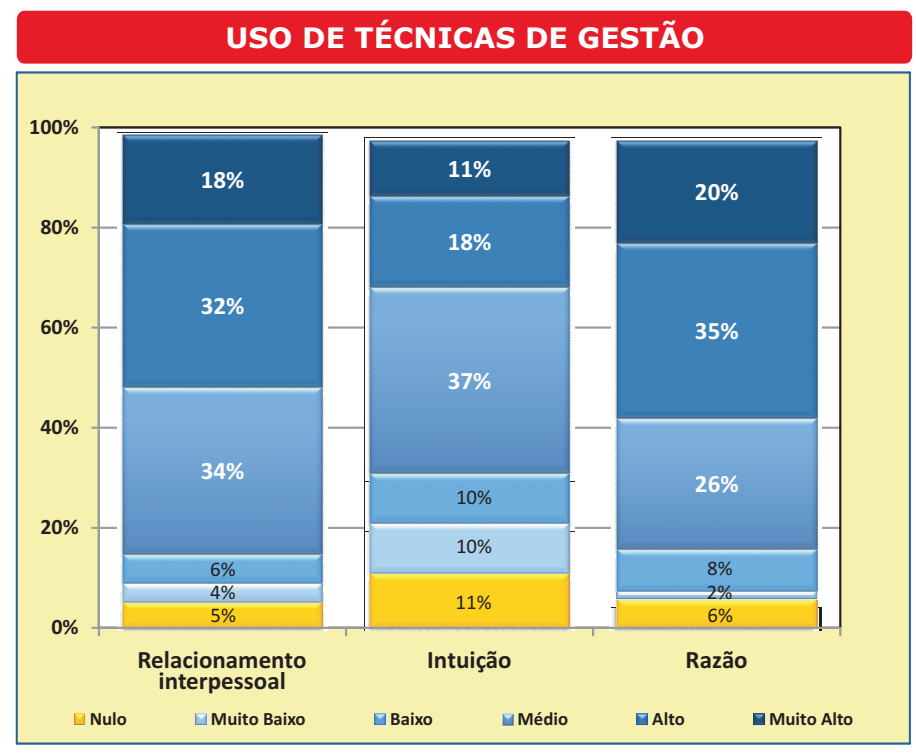

Fonte: Dados primários da Pesquisa (2011)

Quanto ao uso de técnicas de gestão, Relacionamento Pessoal e Razão são utilizados no cotidiano organizacional, mais de $11 \%$ dos respondentes disseram que intuição não faz parte da estruturação de suas técnicas de gestão. Na média, entretanto, os valores são basicamente equânimes entre razão, intuição e relacionamento interpessoal (em torno de 35\% categorizados como médio), de acordo com os dados indicados na Figura 4.

Figura 5 - Relevância dos setores empresariais, segundo a autoavaliação dos gestores

RELEVÂNCIA DOS SETORES | AUTOAVALIAÇÃO

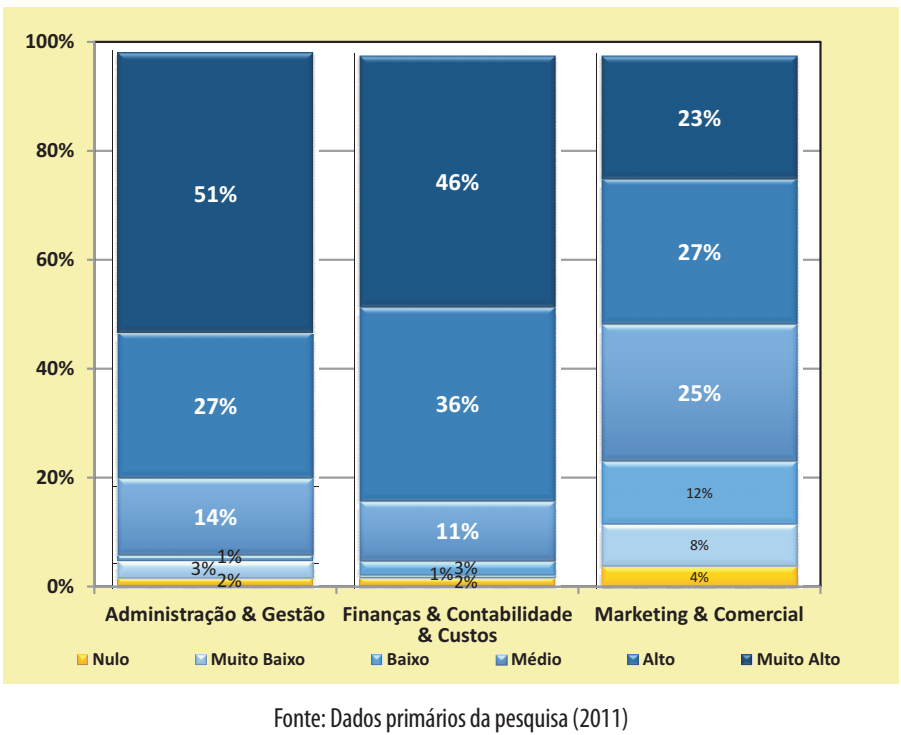

O ICD também avaliou a percepção autoavaliativa dos gestores quanto aos diferentes setores empresariais. (a) Administração/Gestão e (b) Finanças/Contabilidade/Custos foram considerados os mais fundamentais, seguidos por (c) Marketing/Comercial e (d) Produção/Logística. Estruturadamente, percebeu-se que algumas das empresas analisadas não possuem áreas de Recursos Humanos e TI organizadas, visto a maior incidência 
de empresas que indicaram tais setores como de análise não aplicável (em amarelo, nas figuras 5 e 6).

Figura 6 - Relevância dos setores empresariais, segundo a autoavaliação dos gestores

\section{RELEVÂNCIA DOS SETORES | AUTOAVALIAÇÃO}

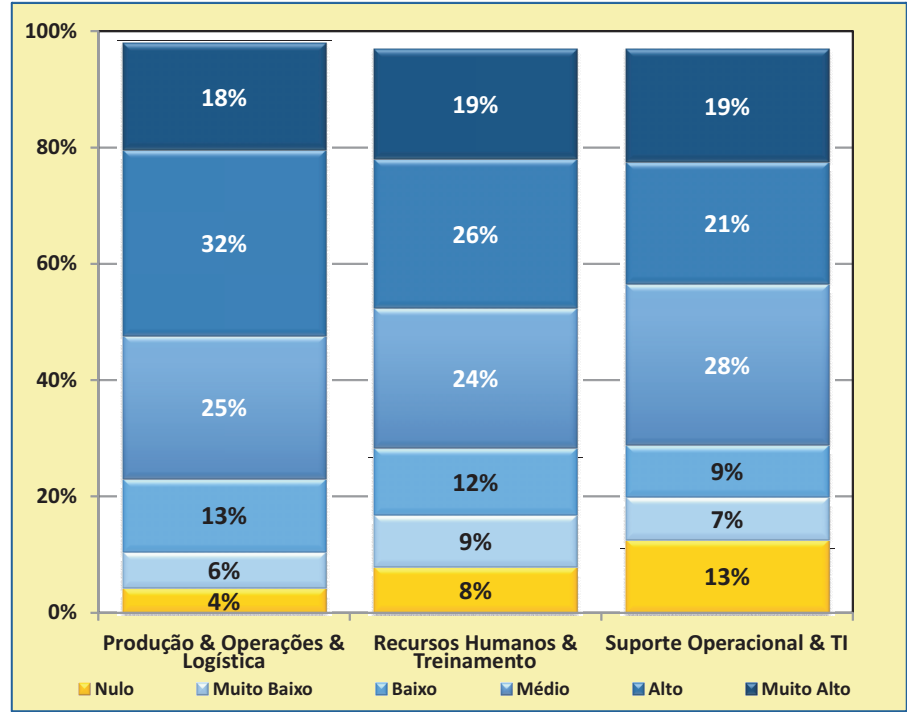

Fonte: Dados primários da pesquisa (2011)

Os pesquisadores procuraram saber a que fatores os empresários creditam o seu sucesso, agrupando-os em cinco diferentes categorias: (a) comunicação eficiente; (b) mão de obra qualificada; (c) treinamento contínuo; (d) TI/Sistemas e (e) responsabilidade socioambiental. Esses fatores resultaram do feedback das entrevistas com perguntas abertas da fase qualitativa da pesquisa, em caráter de pré-teste, em fatores destacados pelos empresários que participaram daquela fase.

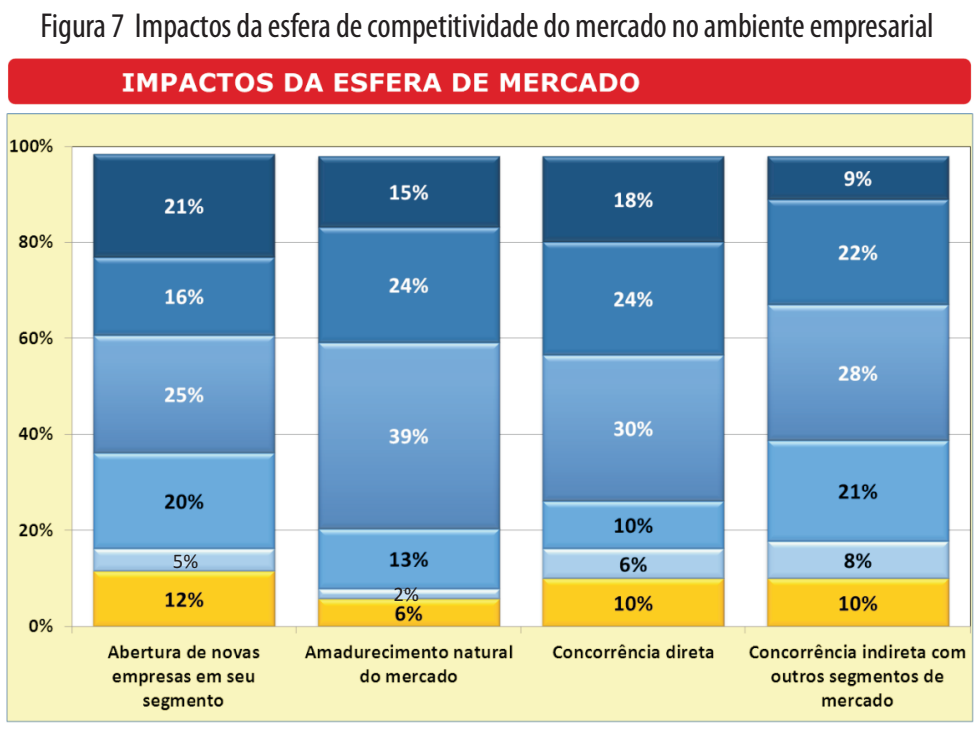

Fonte: Dados primários da pesquisa (2011)

Para os respondentes, fatores em destaque são a mão de obra qualificada (que confirma os aspectos de escolaridade já abordados) e a responsabilidade socioambiental. Os pesquisadores inferem se isso não se dá mediante a própria gênese étnico-cultural das empresas e o ambiente de negócios da microrregião, pois 
historicamente o corpo empresarial regional tem apoiado a comunidade que vive no entorno de suas empresas. O termo que hoje é conhecido como responsabilidade socioambiental é algo corrente nas comunidades ítalo-germânicas que compõem a região.

Embora não haja conflitos de comunicação significativos, como também treinamentos contínuos, indicados como fatores de sucesso, uma das descobertas de pesquisa deu-se pelo crédito menor da TI como uma área fundamental aos negócios da empresa. Os pesquisadores acreditam que haja aí algo que pode ser pesquisado mediante etapas descritivas e confirmatórias posteriores da pesquisa, em novas edições.

0 ambiente de mercado também foi monitorado por meio de outros dois aspectos: clientes e fornecedores. Os dados foram categorizados de acordo com características pré-elencadas pelos respondentes da primeira fase da pesquisa, de modo que na segunda etapa pudesse ser verificada quantitativamente a ocorrência dos fatores elencados.

$\mathrm{Na}$ esfera dos clientes, os principais impactos foram o aumento da exigência dos clientes por qualidade, a comunicação clara e confiável e a fidelização dos clientes. Algo que surpreende, vistos ainda os casos existentes de má-prestação de serviço e/ou de modo amador na microrregião estudada. Conquanto haja menor tolerância ao erro igualmente considerada, os dados conjugados mostraram que, ao existir uma estrutura institucional que administre o erro e o converta em acertos, o cliente pode estar menos suscetível a considerar sua demanda não atendida.

Na socialização dos dados, por ocasião da III Semana Acadêmica Senac, em novembro/2011, o corpo discente efetuou uma coanálise dos resultados de pesquisa. Isso porque, até aquele momento, os pesquisadores não haviam conseguido explorar satisfatoriamente os resultados de que para $7 \%$ o grau de inadimplência era não aplicável ou desimportante. Com a socialização, discutiu-se que tais dados decorrem do fato de que, atualmente, são financeiras terceirizadas quem se responsabilizam pela inadimplência do cliente e, portanto, esse fator segue um padrão diverso dos demais.

Já quanto aos fornecedores, dos três fatores elencados, percebeu-se que há uma comunicação clara e confiável com eles; em seguida, vem a menor tolerância ao erro. Nesse conjunto de fatores, o ponto mais importante vem a ser o descompasso entre as necessidades entre fornecedores e clientes dos serviços.

Por fim, quanto às principais tendências empresariais verificadas, em termos dos benefícios oferecidos, percebeu-se que se situam ainda no tradicionalmente oferecido pelo mercado. De acordo com a Figura 8, dos respondentes, $61 \%$ das empresas oferecem alimentação e transporte, vindo logo a seguir os benefícios de auxílio escolar (31\%) e auxílio médico (28\%). A assistência odontológica, com 17\% e a participação nos lucros, com 14\% vem logo a seguir. Embora proporcionalmente menores, não deixam de ser expressivas no conjunto geral dos fatores elencados.

Figura 8 - Tendências empresariais verificadas

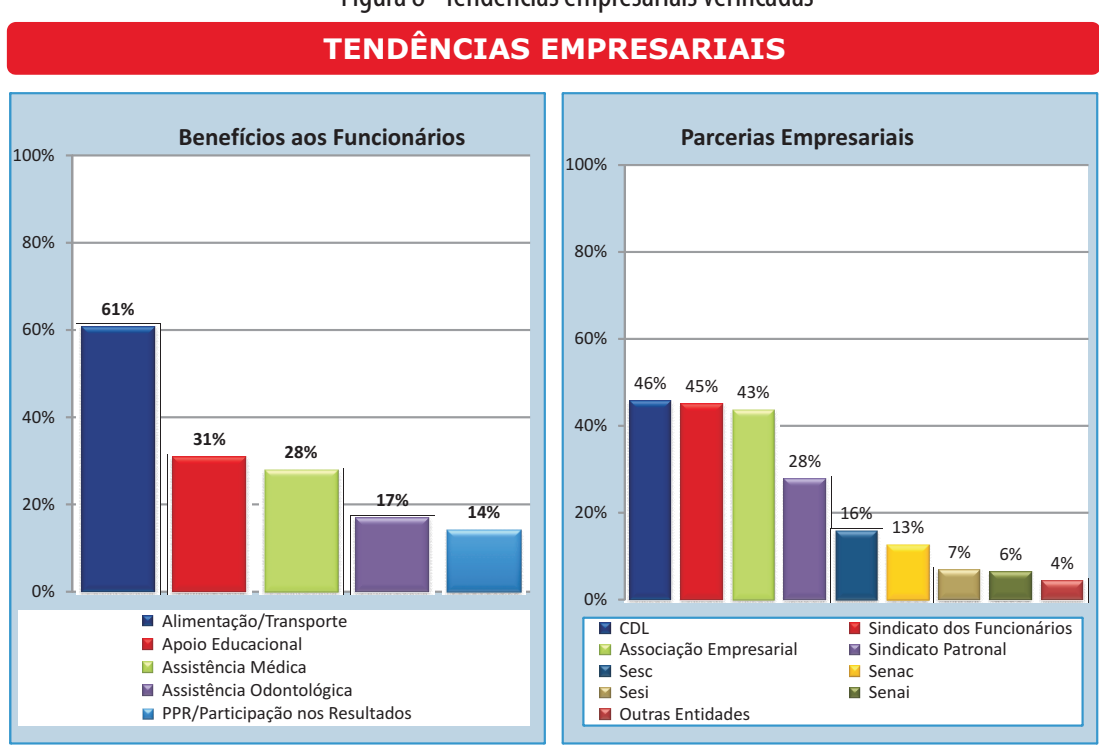

Fonte: Dados primários da pesquisa (2011) 
Ainda pela análise da Figura 8, constatou-se que, das entidades e instituições às quais as empresas são filiadas, aparecem num primeiro plano a CDL (46\%), o Sindicato dos Funcionários (45\%) e a Associações Empresariais da microrregião (43\%). Ainda parceiras, são mencionadas em ordem decrescente: Sindicato patronal, Sesc e Senac, demonstrando que ainda há um campo a ser administrado em termos do relacionamento interinstitucional.

\section{CONSIDERAÇÕES FINAIS}

No início do desenvolvimento da pesquisa, foram antevistas algumas hipóteses aplicáveis à amostra de empresas do universo microrregional de negócios. Quanto à primeira delas, de que a maioria das empresas seguem modelos de gestão não formalizados, com respostas predominantemente tácitas às demandas de mercado, o conjunto de respostas permite afirmar, com razoável certeza, para uma pesquisa exploratória, que tal ocorre de fato. Isso pode ser verificado mediante as parcerias e capacitações realizadas, com presença significativa, mas não majoritária na amostra avaliada, em termos das tendências empresariais pré-listadas.

Outra hipótese, a de que embora seja crescente a busca por conhecimento profissional, a prática ainda carece de bases teóricas; isso foi parcialmente verificado, dado um grau superior de capacitação por parte de gestores e colaboradores das empresas, em vista do que se esperava encontrar. Os dados demonstraram adequada formação por parte de gestores, notadamente nos níveis técnico e superior, bem como apropriada formação por parte dos funcionários, com um grupo majoritário formado por pessoas com nível médio completo.

Por fim, quanto à terceira hipótese de pesquisa, de que há uma relação direta entre o porte das empresas estudadas, o grau de profissionalização de sua estrutura de gestão, e entre este grau e sua faixa de faturamento por período, verificou-se direta proporcionalidade entre tais fatores, que se poderiam complementar e ser mais bem explorados mediante programas estatísticos específicos que pudessem fazer uma correlação desses dados em nuvens de tendências e/ou gráficos de dispersão. Isso permite aferir que há um crescimento estruturado por parte das empresas, que não necessariamente aumentam o seu porte em termos de faturamento e número de funcionários. Mas que, quando o fazem, sustentam-no, o que se pôde verificar mediante a longevidade do grupo de empresas analisadas na pesquisa.

Além dos dados primariamente obtidos, é importante elencarem-se os benefícios complementares obtidos. Assim, os resultados vieram ao encontro da pesquisa como atividade-fim de geração de conhecimento. Percebeu-se que, com o crescimento e estruturação dessas atividades na Unidade, foi imprescindível a comunicação dos pesquisadores com as Coordenações, com os docentes participantes e com os estudantes da Instituição, de modo a disseminar os objetivos e a importância do estudo.

Metodologicamente, a aplicação da pesquisa, realizada pelos acadêmicos da estrutura Senac Jaraguá do Sul, (Jovem Aprendiz, Cursos Técnicos, Cursos Profissionalizantes e Cursos Superiores), deu a oportunidade de que todos pudessem se envolver no processo. Os resultados, no entanto, ainda são irregulares, visto que a criação de uma cultura de pesquisa é algo que pode ser continuamente fomentado.

Aqui, finalmente, os pesquisadores, que são docentes e discentes da Faculdade Senac de Jaraguá do Sul querem fazer um agradecimento especial à Coordenação do Núcleo de Ensino Superior e à Coordenação Estadual de Pesquisa, que oportunizaram a realização desta, como uma diretriz do Conselho Consultivo da Instituição, presidido pelo Diretor desta Unidade. Os pesquisadores também acham justo agradecer a todos os acadêmicos, orientadores e empresas que se envolveram e dedicaram tempo a responder adequadamente ao instrumento de pesquisa proposto. 


\title{
ANALYSIS OF COMMERCE \& SERVICES BUSINESS PROFILE IN VALE DO ITACOPU MICRO REGION
}

\begin{abstract}
For motivation, businesses have surveillance and competitiveness in a constantly changing market place. Companies and entrepreneurs profiles have been changing and new challenges, goals and markets are being searched. Contextualized in northern Santa Catarina, Faculdade de Tecnologia de Jaragua do Sul aimed to focus its efforts in portraying commerce and services business profiles in Vale do Itapocu micro region. So, aiming to relate the management profile of partaking companies, as well as their main managers ones, it sought to align to the analysis of what would be a desired profile for qualified professionals for the upcoming market. Even having an exploratory nature, the research denoted that, among some other hypothesis, most companies in the micro region follow non-formalized management roles, with predominantly tacit answers to market demands. Even though there is an upraising search for professional knowledge, praxis need theoretical basis. That was partially found through to analysis data, given a superior level of professional coaching by part of those companies' managers and employees regarding those initially expected, showing proactivity in commerce and service micro regional industry, considering new demands from new consumption profiles. Stratified data only to commerce and services industry showed a sample composed of mostly commerce companies (66\%), in a range of billing of BRL 244,000 per year (50\%), up to nine employees (49\%) and with more than two years of business activity (92\%).
\end{abstract}

Keywords: Strategic Management. Business Diagnostic. Commerce and Services.

\section{REFERENNCIAS}

ANDREWS, K. R. O conceito de estratégia empresarial. In: MINTZBERG, H.; QUINN, J. (Org.). 0 processo da estratégia. 3. ed. Porto Alegre: Bookman, 2001. Cap. 12.

CHIAVENATO, Idalberto. Gerenciando com as pessoas: transformando o executivo em um excelente gestor de pessoas. Rio de Janeiro: Elsevier, 2005.

FLEURY, M. T. L. O desvendar da cultura de uma organização: uma discussão metodológica. In: FLEURY, M. T. L.; FISCHER, R. M. Cultura e poder nas organizações. 2. ed. São Paulo: Atlas, 1996. Cap. 1.

GIL, A. C. Como elaborar projetos de pesquisa. 4. ed. São Paulo: Atlas, 2002.

GIL, A. C. Gestão de Pessoas: enfoque nos papéis profissionais. São Paulo: Atlas, 2010.

GOMES, F. P; ARAÚJO, R. M. Pesquisa Quanti-Qualitativa em Administração: uma visão holística do objeto em estudo. [2010]. Disponível em: <http://www.ead.fea.usp.br/Semead/8semead/resultado/trabalhosPDF/152.pdf>. Acesso em: 12 maio 2011.

GOMES, E. R. P; KRÜGER, R. E; SANTOS; SILVA, R. A. Consultoria Universitária Jr. Senac — Consus: estudo multicaso sobre diferenciais estratégicos adquiridos por empresas participantes do programa no período 2009/2010. Projeto de Pesquisa. Florianópolis: Senac, 2010.

GURGACZ, G; NASCIMENTO, Z. M. A. Metodologia do Trabalho Científico com Enfoque nas Ciências Exatas. Joinville: Sociesc, 2007.

IBGE - Instituto Brasileiro de Geografia e Estatística. As micro e pequenas empresas no setor de comércio e serviços. Rio de Janeiro: 2001. 
LEMOS, B.; JÓIA, L. Fatores Relevantes à Transferência de Conhecimento Tácito em Organizações: um estudo exploratório. In: Encontro da ANPAD, 33., 2009, São Paulo. Anais do XXXIII EnANPAD. São Paulo: ANPAD, 2009. p. 1-16.

MARCONI, M. A.; LAKATOS, E. M. Metodologia científica: ciência e conhecimento científico, métodos científicos, teoria, hipóteses e variáveis, metodologia jurídica. 5. ed. São Paulo: Atlas, 2007.

MARTINS, O. S.; MONTE, P. A. Motivações, Expectativas e Influências do Título de Mestre em Ciências Contábeis: Uma Análise a Partir dos Egressos do Programa Multiinstitucional UnB/UFPB/UFPE/UFRN. In: Encontro da ANPAD, 33., 2009, São Paulo. Anais do XXXIII EnANPAD. São Paulo: ANPAD, 2009. p. 1-16.

MINTZBERG, $\mathrm{H}$ et al. 0 processo da estratégia: conceitos, contextos e casos selecionados. 4. ed. Porto Alegre: Bookman, 2006.

OLIVEIRA, D. P. R. Planejamento Estratégico: conceitos, metodologia e práticas. 26. ed. São Paulo: Atlas, 2009.

SEBRAE/SC. Santa Catarina em Números. [2010]. Disponível em: <http://.sebrae-sc.com.br/scemnumero>. Acesso em: 12 maio 2011. 